\title{
Livro-Arte: uma possível aproximação
}

\author{
Marina Attiná Jozala Barros \\ UFSM - Universidade Federal de Santa Maria
}

\section{Resumo}

Este artigo é parte da minha dissertação de mestrado, a qual é composta de observações, reflexões, análises e abordagens realizadas a partir da minha própria produção em livros-arte. Estabelece aproximações com a obra da artista Luise Weiss, com o intuito de demonstrar e colaborar com a presença da linguagem visual do livro-arte no Brasil e na arte contemporânea. Percebeu-se com esse trabalho que a linguagem visual do livro-arte está presente no Brasil, mas é pouco abordada por teóricos da arte em nosso país. E que a partir de aproximações entre trabalhos de artistas também surgem diferenças, as quais só valorizaram o meu trabalho como artista.

Palavras-chaves: Arte contemporânea; Livro-arte; Luise Weiss.

\section{Abstract}

This article originates from my master's degree thesis, which contains observations, reflections, analyses and perspectives made from my own book art production, establishing approaches with artist Luise Weiss' work in order to demonstrate and collaborate with the presence of book art's visual language in Brazil and in contemporary art. With this work it was noticed that book art's visual language is present in Brazil but has little space among art theorists in our country. It has also demonstrated that when approaches are made between artists' works, differences between them also arise and that just valued my own work as an artist even more.

Keywords: Contemporary art; Book Art; Luise Weiss.

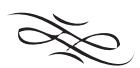

\section{Introdução}

O objetivo da minha pesquisa de mestrado é pontuar possíveis aproximações, entre duas artistas, estabelecidas a partir de um breve relacionamento acadêmico com 
a artista, gravadora, fotógrafa, professora, Luise Weiss ${ }^{1}$; por meio da análise de questões conceituais e formais na linguagem do livro-arte (meio de expressão artística utilizado por mim e por Weiss), assim como utilizando a entrevista que foi realizada com Weiss durante a pesquisa.

Defini que utilizaria essa abordagem a partir de escolhas e indagações que foram sendo identificadas ao longo do meu percurso como artista, principalmente após o término da graduação e na busca pela realização do mestrado.

A linguagem visual do livro-arte já tinha sido explorada durante o meu trabalho de graduação, porém de forma mais branda, e, por ter sido abordada apenas no final do curso, apresentou-se como um incentivo para a continuação de uma pesquisa acadêmica nessa área. Dessa forma, mesmo concluído o Curso de Artes Plásticas, continuei a reunir materiais sobre o livro-arte e pude me dedicar à escrita do projeto para a inserção no mestrado.

Assim, este artigo visa apresentar as aproximações realizadas no decorrer do mestrado a partir de aspectos de minha própria obra e da obra de Weiss. O conteúdo deste reúne seis de dez obras que realizei para o mestrado produzidas a partir da leitura de bibliografias e do contato com artistas e incentivadores, o que resultou na exteriorização de diversos momentos em arte. Cada um dos livros-arte criados para esse projeto dialoga principalmente com a obra de Luise Weiss, as quais quatro estão presentes nesse artigo, mas também conversa com outros artistas, livros e autores.

\section{Aproximações e diferenças}

O meu trabalho, assim como o de outros investigadores dentro do ambiente das artes visuais, está relacionado às questões de "temporalidade" descritas por Paulo Silveira (2008), assim como questões que envolvem o leitor/observador, neste caso específico, o "outro". Esse texto aborda os critérios que aproximam e diferenciam os meus livros-arte e os de Luise Weiss, a partir de comparações conceituais e formais encontradas nos "tempos" de cada artista.

Encontrei nas proposições de Paulo Silveira, reflexões sobre a temporalidade nos livros-arte, de forma a especificar algumas características presentes nessa linguagem, e acredito que esses aspectos estão presentes em meus próprios livros-arte abordados nesse texto.

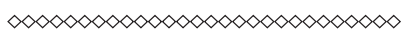

1 Luise Weiss (São Paulo SP 1953). Gradua-se em artes plásticas, em 1977, pela Escola de Comunicações e Artes da Universidade de São Paulo - ECA/USP. Paralelamente à graduação, realiza livros com suas xilogravuras. Inicia sua carreira como professora universitária em 1984, lecionando na Faculdade de Artes Alcântara Machado - Faam, e desde 1985 dá aulas na Universidade Presbiteriana Mackenzie. Mestre, em 1992, pela ECA/USP, conclui o doutoramento em 1998, na mesma universidade, com a tese Retratos Familiares: in Memorian. Fonte: http://enciclopedia.itaucultural.org.br/pessoa9394/luise-weiss 
Mas num livro de artista, sua inerência especial deve estar projetada no seu objetivo: ele se propõe a um desfrute além da leitura convencional (ou tradicional). O livro de artista não é, absolutamente, literário (embora possa conter literatura). O tempo pode estar além da elocução. Pode estar na sua realidade cronológica (histórica). Pode estar no momento perceptivo do fruidor. Pode ser a duração de seu próprio desfrute, ou a sua própria proposta (assunto). Em todo caso, sua evidência estará potencializada pela concepção plástica da obra, na qual a estrutura é um predicado semântico (SILVEIRA, 2008. p. 73).

A partir dessas colocações feitas por Silveira, procuro relacionar os meus próprios livros-arte com as temporalidades que o autor apresenta. Algumas delas mais evidentes, outras muito pouco.

Percebi ao longo da realização do mestrado que cada livro-arte produzido por mim é a narração de um sentimento, de uma emoção. Ao elaborá-los, desenvolvê-los e torná-los objetos palpáveis supro a necessidade de manifestar-me através da escrita, quase havendo uma substituição do objeto diário (os quais escrevo desde 1995) pelo objeto livro.

A artista Luise Weiss está presente no trabalho de mestrado como um símbolo que representa a importância dos outros em minha obra. Eu poderia ter escolhido outros artistas, mas foi Luise Weiss que me mostrou o caminho para transferir sentimentos e emoções aos outros, e este foi através do livro-arte.

Parte do meu trabalho foi desenvolvido tendo como foco livros realizados no decorrer de 2014, quando o objetivo principal era dialogar com os livros-arte de Luise Weiss. Eu pretendia criar livros-arte que tivessem características e/ou técnicas que fossem utilizados por Weiss. Acredito que, no processo de criação de cada um deles, eu estava muito envolvida com as propostas às quais me dispus, mas, como a presença das obras de Weiss era muito forte, acabei por envolver em meu trabalho sentimentos originados dessas observações sobre formas dos trabalhos, temáticas, materiais utilizados.

Posteriormente, em 2015, as diferentes leituras e proposições expositivas me levaram a ter mais autonomia e liberdade. Foi se instaurando, cada vez mais, a ideia de que, em um diálogo, existem vozes dissonantes e consonantes; cada artista, principalmente se tratando de mim e de Luise Weiss, temos históricos, vivências, experiências diferentes, algumas podem se encontrar em alguns pontos, porém continuam sendo duas pessoas completamente diferentes. Nesse período, as diferenças e as aproximações começaram a se tornar mais claras, e pude criar livros-arte que fossem mais meus e menos dessa relação que eu esperava encontrar com as obras de Weiss. 


\section{"No escuro" e "Espelho d'água"}

O livro-arte "No escuro" (2014), Figura 1, é uma de minhas propostas que mais consegue traduzir os sentimentos por trás do "eu”. Ele descreve momentos de aflição, como por exemplo, a morte, uma doença ou uma mudança para uma cidade distante, e que foram restaurados conforme o passar do tempo; momentos estes que podem ser vivenciados por qualquer um e, por isso, quando o "outro" encontra-se com o livro "No escuro", sente-se tocado.

O pensamento que perpassa o livro "No escuro" surgiu em 2012, a partir de um trecho de uma música que eu estava ouvindo na época e que me chamou atenção: "É no escuro que se aprende a ver" (Rosa de Saron. Jamais Será Tarde Demais, 2012). Essa música, entre todas as outras do álbum da banda, fez-me pensar sobre o que exatamente a letra queria dizer com "É no escuro que se aprende a ver", e assim surgiu a ideia de criar o livro-arte em questão.
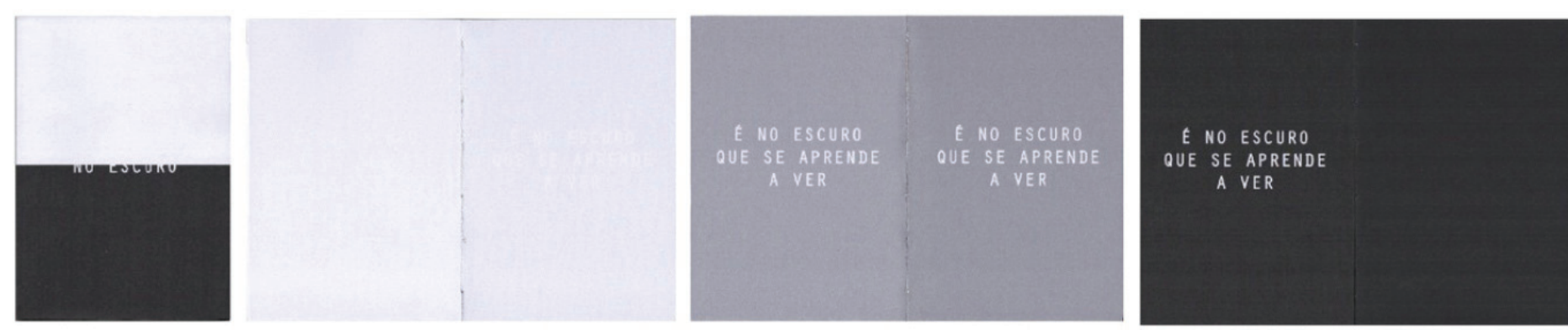

Fig. 1 - "No escuro", de Marina Attiná Jozala (2014). Impressão sobre papel. 14,5 x 20,5 x 0,5 cm. Fotografia: Marina Attiná Jozala.

Com o tempo, aprendemos que estar no escuro, seja física ou metafisicamente, às vezes, é a maneira mais fácil de superar as dificuldades. Assim, como os olhos se acostumam com o escuro e passamos a ver o que está em volta, a vida está cheia de dificuldades, mas aprendemos a valorizar mais o que temos. Com esse livro-arte, eu tentei demonstrar de uma maneira simples o momento em que nos acostumamos com o escuro e passamos a ver a luz, as coisas boas que a vida tem a oferecer.

Uma aproximação entre as artistas Marina e Luise Weiss acontece considerando o negro presente em gravuras de Weiss e da intencionalidade da artista em encontrar a luz na matriz escura. A pesquisadora Ana Paula Nascimento (2007, s/p) fala dessas obras de Luise Weiss, da sua paixão pela luz e dos significados por trás das escolhas da artista ao utilizar essa linguagem. 
Luise, por sua vez, igualmente trabalha o negro, mas este aliado às sombras, com inúmeras nuances intermediárias, até a chagada ao branco. Memória, passado, presente, ausência, permanência, lembrança e esquecimento formam o imenso extrato do qual suas obras emergem. Não apenas nos retratos dos familiares ou dos desconhecidos - na atualidade a sua produção mais conhecida -, mas também nas plantas, objetos, flores e animais, manifestando talvez a inconsciente influência germânica da paisagem até certo ponto fantástica, de uma figuração expressiva, de paixão pela luz.

O livro-arte "No escuro" expressa momentos difíceis que foram superados. Quanto à obra de Luise Weiss, acredito que demonstra muitos aspectos de sua memória, da de sua família e da de pessoas que também passaram por momentos complicados na vinda para o Brasil, fugindo da guerra. Também creio que todos passamos por momentos que nos deixam no escuro e por outros momentos que nos levam a viver na luz. Esse livro-arte, assim como os livros de Weiss, demonstra a simplicidade dos sentimentos que permeiam a arte, assim como a simplicidade na materialização desses sentimentos utilizando a própria arte.

"Espelho d’Água" (2014), Figura 2, é um livro que, além de retomar vivências da infância a partir de lembranças que tenho de quando era pequena e ia pescar com a minha família, de quando fazia aulas de natação, ou ia à praia durante as férias; também retrata o "eu presente", pois, a cada leitura e virada de página, o observador será refletido de uma nova forma, assim como se olhar no espelho a cada dia e ver o tempo passando.
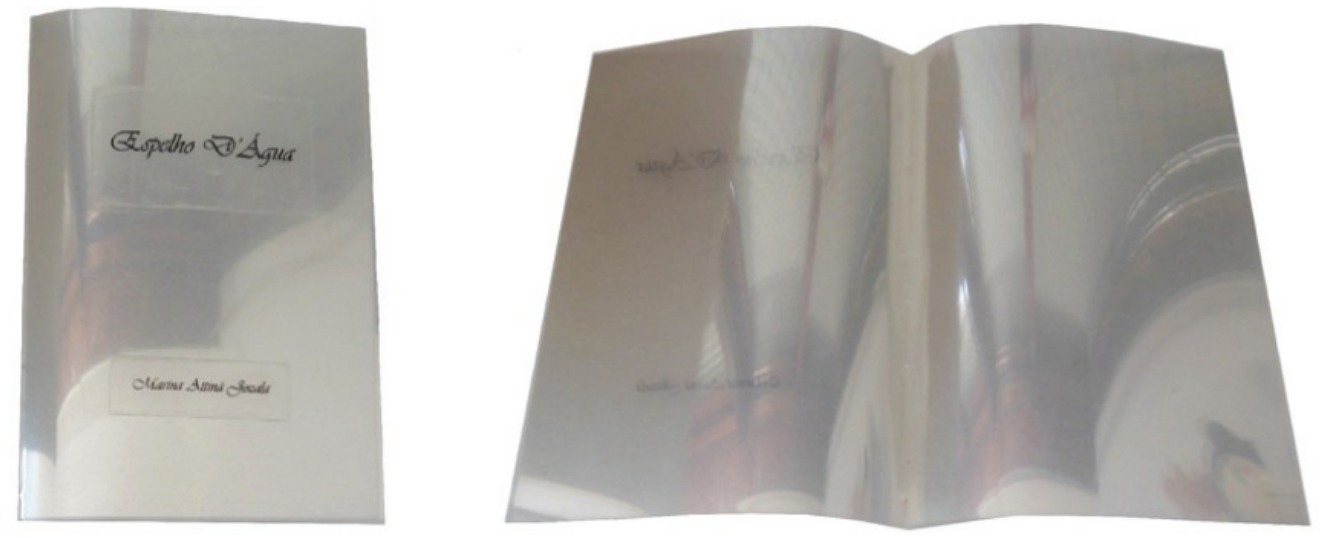

Fig. 2 -“Espelho d’Água”, de Marina Attiná Jozala (2014). Acetato transparente e impressão. 15 x $21 \mathrm{~cm}$. Fotografia: Marina Attiná Jozala.

Esse livro-arte também utiliza um mesmo conteúdo abordado por mim e por Luise Weiss, mas colocados de forma diferente. A intenção por trás deste era que todas 
as páginas juntas continuassem tendo uma transparência, na qual o leitor virasse as páginas mantendo o olhar a um resquício dos elementos que estivessem por baixo. Porém, quando realizei o projeto e juntei as páginas, essa transparência deixou de existir. As páginas juntas causaram um espelhamento em que o leitor se vê olhando para o livro, mas de maneira deformada, como se olhasse para um lago. Conforme o leitor movimenta o livro-arte, move-se com ele - por isso, o título.

Paulo Silveira (2008) defende que o tempo do livro é mutável, ele descreve esse tempo como algo que muda por causa de interferências externas, como um livro amarelo ou comido por traças. No caso do "Espelho d’Água”, ele é mutável devido à sua leitura, à sua interpretação e ao lugar que o leitor escolhe para ler, pois conforme o leitor muda, o livro muda com ele.

Quando estava reformulando alguns conceitos sobre as obras de Luise Weiss, deparei-me com o livro-arte "Olho d’Água" (2012), Figura 3, que mostra fotografias/ retratos recortadas formando ondas, como quando estamos olhando para a água, derrubamos algo e o reflexo de nosso rosto fica deformado. Weiss descreve esse movimento criado ao interagir com a água por meio do toque, e, no caso de "Espelho d’Água", o leitor interage por meio da visão; pontos de vistas diferentes sobre um mesmo elemento, a água.
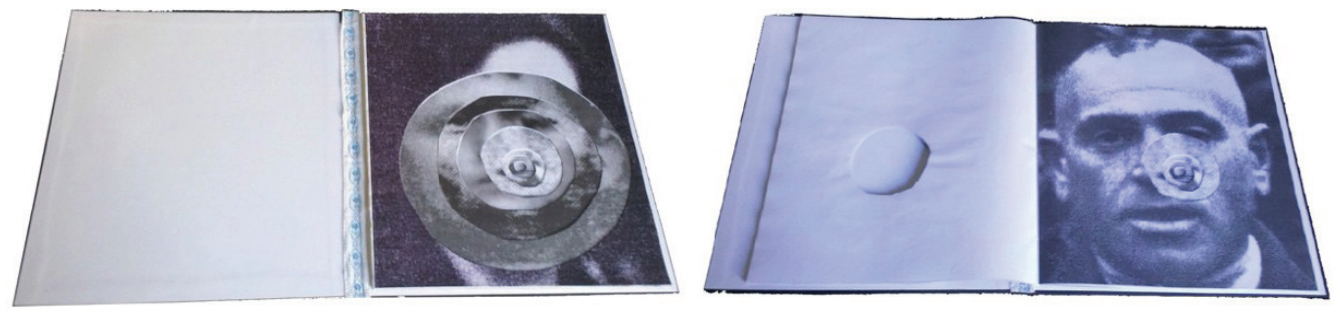

Fig. 3 - "Olho d'água", de Luise Weiss (2012). Cópia colorida. 36 x 31 x 1,5 cm. Fonte: Acervo Luise Weiss.

Sobre seu livro-arte, Weiss (2015) em entrevista relata:

O livro Olho d’Água surgiu na Polônia, num workshop de 2012. Tinha um rio, um velho moinho, perto do atelier, e eu tentei várias vezes fotografar a água com os círculos concêntricos quando algo cai nágua. Observando no final as cópias xerox de retratos, num momento tudo se uniu, o olho d'água do riacho, as xerox.

Nesse sentido, ainda que partindo de diferentes proposições, ambas coincidimos na tentativa de formalização de um livro no qual o elemento água serve para refletir quem está observando. 
Ambos os livros-arte, "No escuro" e "Espelho d’Água”, abordam questões poéticas literárias e, apesar de não ser de forma intencional, em meu trabalho a utilização desse caráter tem acontecido recorrentemente. Por esse motivo, resolvi buscar referências da poesia concreta em meus livros-arte, a qual é descrita de forma breve a seguir:

Depois de 1950, revelando influências de Mallarmé, Pound, Joyce, Apollinaire, Gomringer, veio surgindo um movimento poético inspirado no concretismo pictórico, caracterizado pela redução da expressão a signos concretos, que visem à apresentação direta do objetivo pela organização de elementos básicos da linguagem em representações gráficas. É um esforço de aprofundamento visual do vocábulo, de isolamento dele em relação aos possíveis conteúdos (afasta-se da poesia "conteudística") [...] (AFRÂNIO COUTINHO, 1972, p. 295 apud FRANCHETTI, 2012, p. 21).

A citação merece destaque nesse segmento, uma vez que descreve a poesia concreta como poemas que foram "simplificados", como é possível notar em "redução da expressão de signos" e "afastamento da poesia 'conteudística". "No escuro" e "Espelho d’Água" não deixam de ser livros literários que também foram "simplificados". Não estou desmerecendo a poesia concreta e muito menos a linguagem do livro-arte; pelo contrário, considero que essas novas leituras nas artes dão origem à arte contemporânea, que são essas nossas formas de interpretar e reinterpretar que descrevem as fases da arte.

Nos livros-arte de Luise Weiss, podem ser encontradas características da poesia concreta, mas, após o estudo de sua obra, acredito que a própria artista não faz nenhuma relação com essa proposta. Em 2014, foi lançado o livro-arte, do qual Weiss participa intitulado "30 Fragmentos de Poesia - Um livro de artista”, organizado por Vinicius Almeida. Porém, esse título remete mais aos elementos conceituais poéticos do que à própria poesia concreta. Dessa forma, com base no que foi exposto sobre a relação de meus livros-arte com a poesia concreta e visual, existe, na relação da poesia concreta com minha obra, um distanciamento entre algumas de minhas propostas e as de Luise Weiss.

\section{"Curiosos habitantes do mar"}

O livro-arte "Curiosos Habitantes do Mar" (2014), Figura 4, tem pontos-chaves que remetem ao mundo infantil, como o fato de ser produzido com elementos coloridos, de se tratar de um livro que atrai o público desse mundo; além de sua própria relação com as águas, pois remete diretamente à minha infância, quando eu pescava frequentemente com a minha família. 


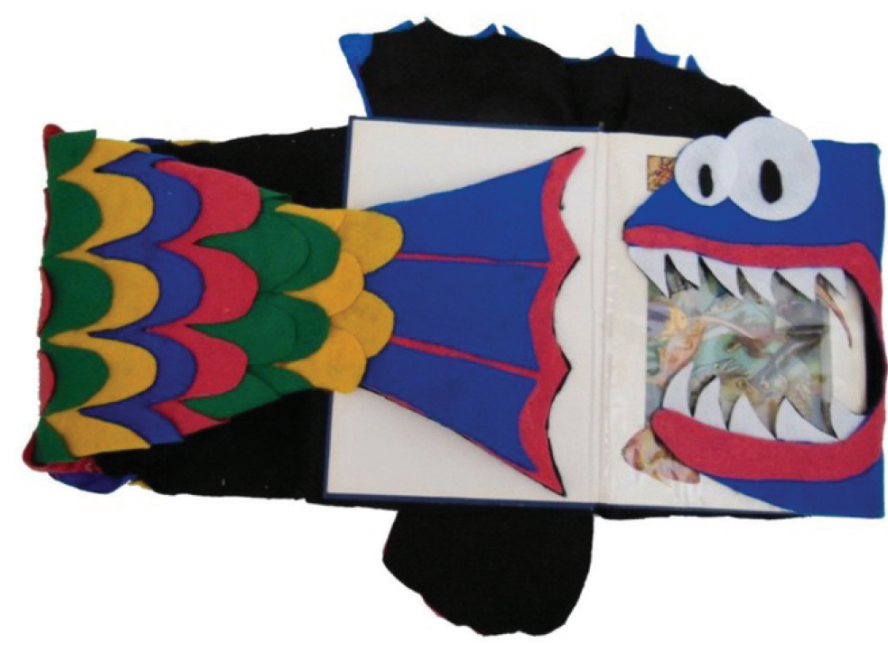

Fig. 4 - "Curiosos Habitantes do Mar", de Marina Attiná Jozala (2014). Livro capa dura, feltro, papel e acetato transparente. 21 × $39 \times 5 \mathrm{~cm}$. Fotografia: Marina Attiná Jozala.

Este livro foi realizado a partir da proposta feita pelo grupo Arte Impressa ${ }^{2}$ no final de 2014, na qual cada integrante teve que escolher um livro nas prateleiras do Sebo Café, na cidade de Santa Maria/RS, e fazer deste um livro-arte - nesse caso específico, um livro-alterado, ou livro-modificado. Após realizadas as alterações, os livros foram colocados nas mesmas prateleiras de origem para ficarem à mostra na exposição "Livro Interferido". Uma segunda exposição, denominada "Livro Interferido II", foi realizada na cidade de Porto Alegre/RS, no final de 2015, quando foram expostos alguns livros do grupo Arte Impressa e livros de artistas porto-alegrenses - o livro "Curioso Habitantes do Mar" também estava presente nessa mostra.

Paulo Silveira (2008, p. 86), utilizando os conceitos temporais, explica onde se encontra o livro-alterado/modificado:

O segundo grande grupo de ocorrências temporais no livro de artista é aquele em que o artista busca a personificação do tempo. Com frequência, ele aqui é muito menos físico pelo movimento do que pela imobilidade, chegando até a ser uma vítima do tempo: ser climático. Sequencialidade e narração têm valor quase nulo. A obra, isso sim, procura a marca física do dano.

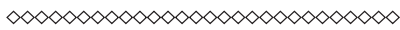

2 Criado em 2012, o Grupo de Pesquisa Arte Impressa é coordenado pela professora doutora Helga Correa, do Curso de Artes Visuais da UFSM, localizada em Santa Maria, Rio Grande do Sul. (...)" "O Grupo de Pesquisa Arte Impressa desenvolve trabalhos nos quais busca expandir o conceito de construção reflexiva usando, entre outros modos, do formato livro. A partir de diferentes abordagens formais, pretende mostrar a inesgotável capacidade da arte em provocar reflexões, sentimentos, propiciar novos questionamentos e leituras sobre temas da realidade atual” Fonte: http://w3.ufsm.br/livrosdosartistas/index.php/o-grupo\# 
Nesse grupo, está incluso o “Curiosos Habitantes do Mar”, pois se encaixa na categoria de "livros encontrados, que são utilizados como matéria-prima para intervenções críticas, por pigmentação, recorte, perfuração, etc.” e nos quais “[...] predominam os exemplares em peça única, muitas vezes com algum vínculo com a escultura” (SILVEIRA, 2008, p. 87).

Para compor esse exemplar recortei as imagens dos peixes que ilustravam o livro, colei todas as páginas formando uma camada só e retirei o miolo do livro para colocar os peixes recortados. Para tanto, usei cola e fita banana para dar profundidade e, por fim, colei uma transparência sobre tudo, remetendo à ideia do aquário.

Ao trabalhar com uma proposta distante do objetivo principal desta investigação estabeleceu-se um novo desafio. Após sua elaboração, lembrei que Luise Weiss também produz livros infantis. O livro "Dentro do Espelho" (2002), Figura 5, da artista, não deixa de ser um livro-arte, principalmente se tratando do livro original, em que a artista criou as colagens. A respeito do objeto livro, ela diz: "Aliás, o livro sempre me cativou, seja do tipo sequencial, álbum ou livro-objeto" (WEISS, 2002, contracapa).

Em palavras de Luise Weiss (2015, entrevista) sobre essa obra:

Dentro do Espelho" surgiu de uma "brincadeira" da imagem espelhada que inverte a escrita, assim como a gravura inverte o texto, as imagens... O livro surgiu a partir de um desenho que estava num quadro negro, numa festa de aniversário do meu pai, garoto. Imaginei aquela figura em formato de lua, saindo, conversando... assim surgiu.

A aproximação entre "Curiosos Habitantes do Mar" e "Dentro do Espelho" ocorreu em função de suas diferenças. No entanto, apesar de os temas abordados nos dois

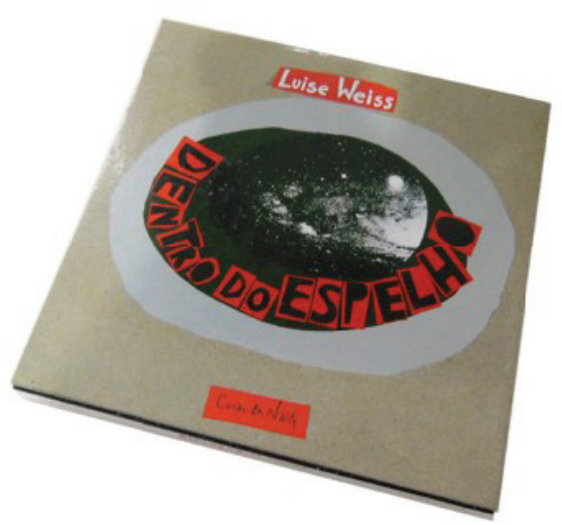

Fig. 5 - "Dentro do Espelho", de Luise Weiss (2002). Impressão sobre papel. $21,8 \times 21.3 \mathrm{~cm}$ Fotografia: Marina Attiná Jozala.

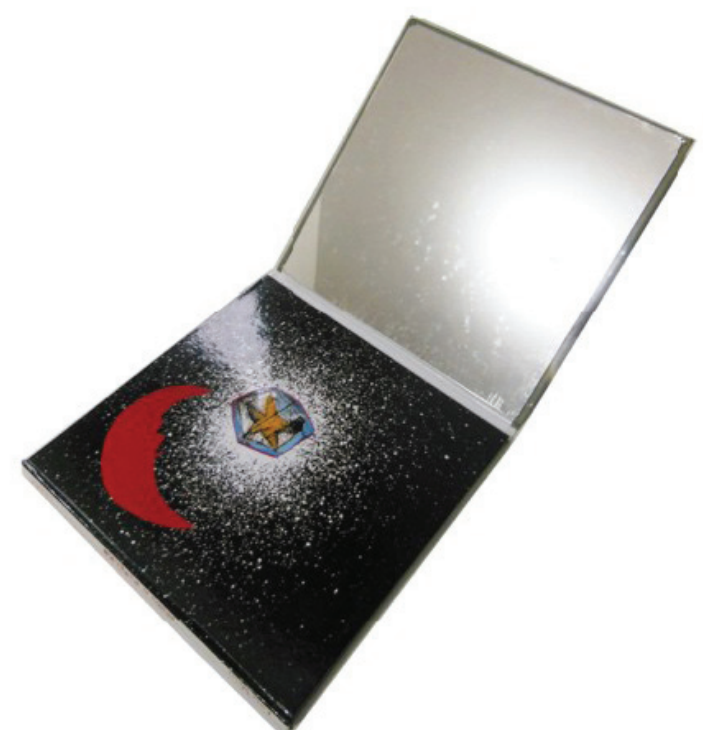


livros serem distintos, houve novamente uma proximidade na liberdade das artistas, dessa vez relacionada ao universo da literatura infantil, por meio do livro-arte.

\section{"Vitrais"}

Antes de apresentar o livro-arte "Vitrais", Figura 6, gostaria de comentar a presença da transparência em meus trabalhos; presença essa que, no início de minha carreira, ainda era incipiente e veio progredindo gradualmente até os dias atuais.

A transparência para mim é um meio de demonstrar meus sentimentos, externá-los de maneira clara; é um meio que utilizo para me sentir bem comigo mesma e com os outros. A transparência é uma das formas que encontrei para traduzir os sentimentos que vivencio em meu cotidiano, principalmente os bons. Ela me permite vivenciar coisas que o opaco nunca deixaria, ela permite que eu veja além, que eu veja o que está por trás e que eu compartilhe com os outros essas vivências através de meus trabalhos. São esses sentimentos bons que procuro passar ao criar um livro-arte utilizando esse elemento.

"Vitrais" (2014) foi inspirado em diversas fotos de vidraças que tiro em viagens; a cor, a transparência, a forma como foram feitas me encanta, o que me motiva a fazer essa coleção de imagens. Esse livro-arte é um pedaço dessas viagens, desses momentos em que estive conhecendo lugares novos e vivendo diversos sentimentos.

Desde 2007, eu já tinha certo interesse pela impressão de fotografias em acetato transparente, mas, com o passar dos anos, deixei isso de lado, conforme eu ia conhecendo e me identificando com outras linguagens visuais e técnicas na arte. Foi apenas em

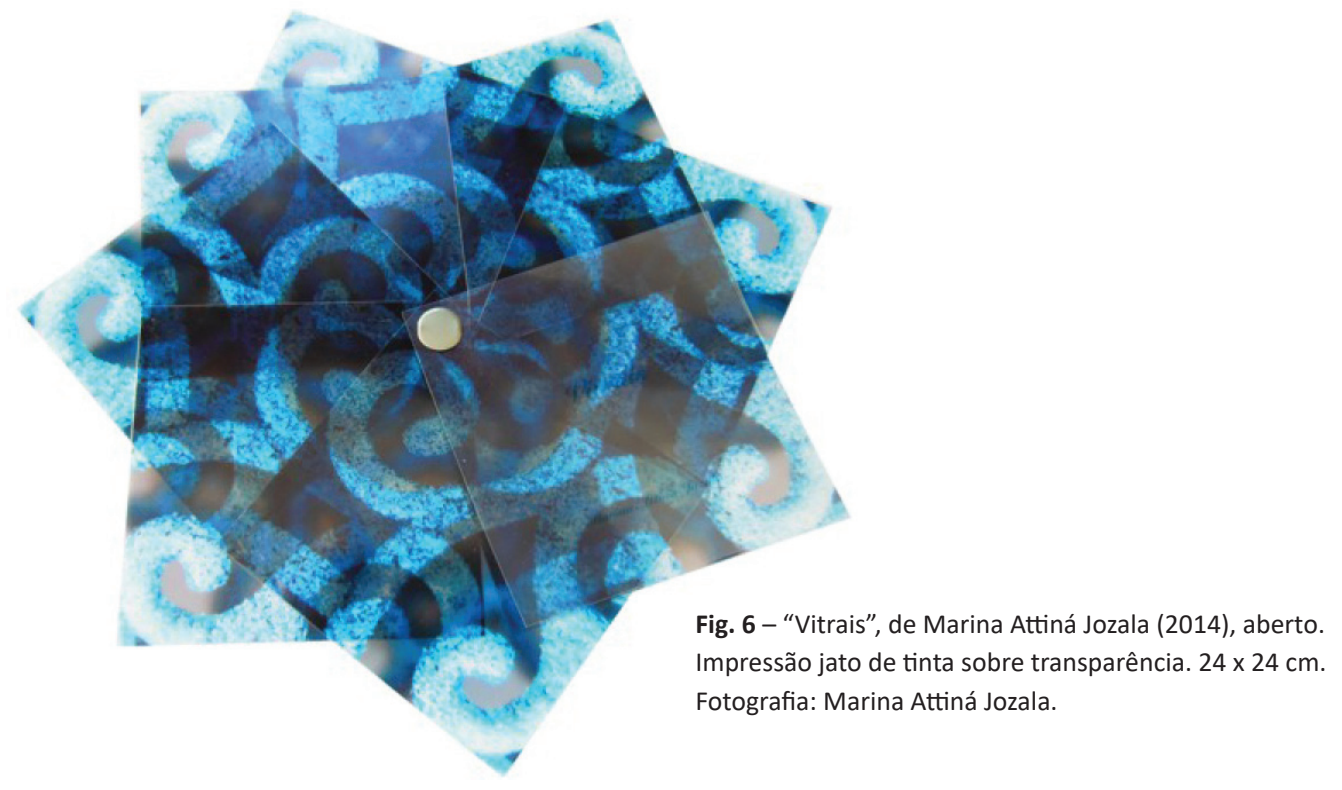


2014, com o início do mestrado, que pude identificar a relevância e o significado específico do emprego da transparência em minha obra.

Para Luise Weiss, que utiliza a transparência em seus livros-arte, esta representa “[...] a 'travessia, 'água,' 'mar', como metáforas de viagem/vida/morte e nostalgia. As transparências deixam transparecer, ora escondem, ora revelam... como ir e vir. Vida e Morte" (WEISS, 2015, entrevista). A meu ver, as palavras citadas por Weiss, como água, viagem, vida e, principalmente, nostalgia, a qual me faz pensar em minhas lembranças, viagens, e sentimentos por trás de acontecimentos, estão diretamente relacionadas ao meu trabalho e à minha pesquisa como um todo.

$\mathrm{O}$ fato de esse livro-arte ser pequeno e remeter às minhas viagens e lugares que visitei, traz uma característica peculiar: é como se ele fizesse parte de cada um desses lugares que frequentei, como uma recordação, uma folha ou pedra pegas no chão. $\mathrm{O}$ "Vitrais", apesar de pequeno, contém muitas lembranças de tempos que foram preservados e recapitulados em forma de livro. Luise Weiss faz o mesmo em suas obras. Retomando momentos que foram vivenciados por ela e por outros, ela revive e traz a nós essas lembranças, as quais, como Silveira (2008) diz, são "maleáveis" por serem colocadas como livros, como objetos que fazem parte da arte.

Para que o livro-arte se tornasse um vitral, ou quase isso, lembrei de um estilo de encadernação que Luise Weiss usou em um de seus livros-arte, "Gira Gira” (2011), Figura 7, completando, assim, o meu projeto. Esse foi produzido a partir de frames de um vídeo dos anos 50/60, com imagens de pessoas desconhecidas. O formato em leque, para Luise Weiss (2015, entrevista), "cria a visualidade de um gesto, um movimento".

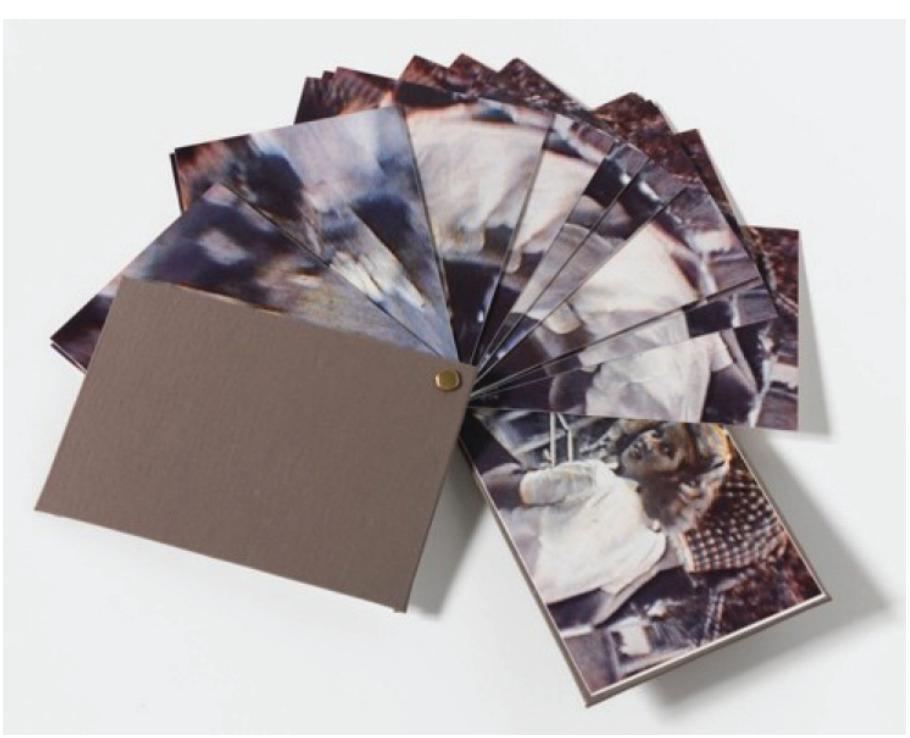

Fig. 7 - "Gira Gira”, de Luise Weiss (2011). Fotografia. 10,5 × 15,5 × $2 \mathrm{~cm}$. Fonte: Acervo Luise Weiss. 


\section{"Fínigans Ueiqui"}

O livro-arte "Fínigans Ueiqui" (2015), Figura 8, foi criado a partir das sensações causadas pela leitura da obra homônima do escritor irlandês James Joyce, a qual me causou certa confusão, pois eu não consegui entender seu contexto em meio aos neologismos e às onomatopeias empregadas pelo autor. Ao interagir com meu livro-arte, devido à presença da transparência e da sobreposição das palavras criadas por James Joyce, o "outro" poderá sentir uma confusão semelhante.

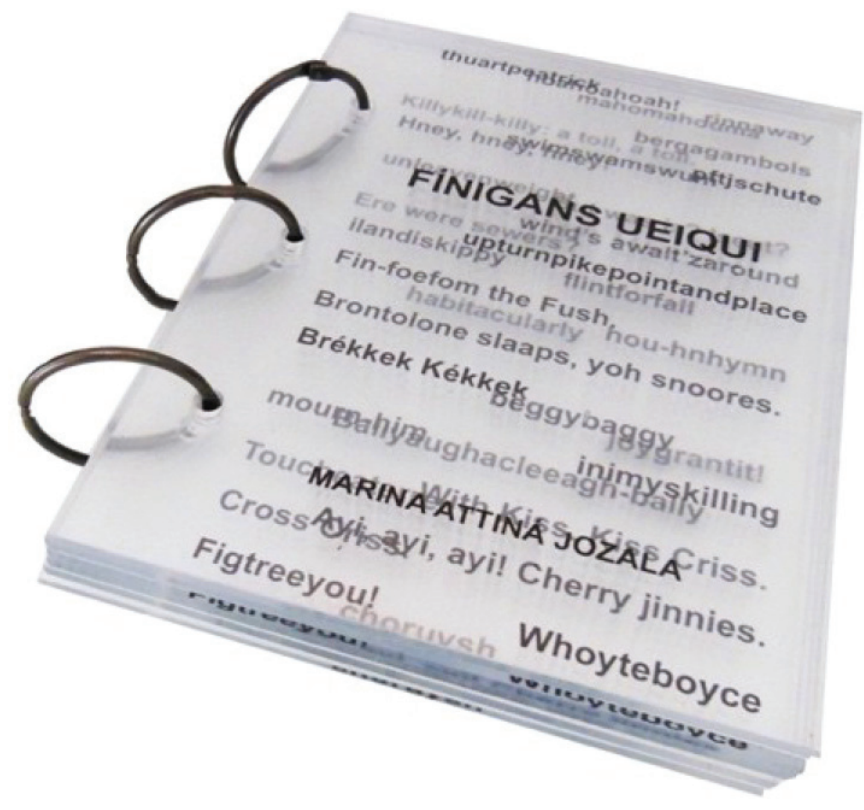

Fig. 8 - "Fínigans Ueiqui", de Marina Attiná Jozala (2015).

Acrílico transparente e impressão adesiva. $17 \times 20 \times 2 \mathrm{~cm}$.

Fotografia: Marina Attiná Jozala.

Desenvolvi esse livro-arte para outra proposta apresentada pelo grupo Arte Impressa, cujo tema era "James Joyce". Cada um pôde escolher uma obra do autor e desenvolver um livro-arte a respeito dessa para ser exposto durante o Bloomsday ${ }^{3}$, em Santa Maria/RS, em junho de 2015.

Eu escolhi a última obra de Joyce, "Finnegans Wake" (publicação póstuma em 2013), a qual apresenta uma estrutura diferente da comumente usada, e preferi ler a versão original em inglês, pois a versão em português perde muito do caráter original e da proposta de James Joyce; uma vez que, ao traduzir para o português, ou outra língua,

$\infty<\infty<\infty<\infty \times \infty \times \infty \times \infty \times \infty \times<\times<\times<\infty$

3 "Realizado em Santa Maria desde 1994, o Bloomsday é uma celebração da publicação de "Ulysses" por James Joyce. O evento acontece em dezenas de cidades pelo mundo e congrega pessoas, línguas e experiências que unem o popular e o erudito, aproximando profissionais da área da literatura e curiosos não especialistas". Fonte: http://site.ufsm.br/noticias/exibir/professores-da-ufsm-participaram-das-atividades-do 
o tradutor precisa recriar as palavras criadas por Joyce, portanto todas as características do autor passam a ser desse novo "autor", fazendo dessa obra uma versão nova.

Em "Finnegans Wake", Joyce cria novas palavras cheias de sonoridade, algumas inventadas usando línguas diferentes. O livro em si é complicado de ler, eu mesma não consegui chegar até o final, pois não pude entender o contexto ou a história como um todo.

A partir dessas qualidades do livro, resolvi elaborar um livro-arte que demonstrasse, em parte, esses sentimentos que perpassaram minha leitura da obra. Como já vinha utilizando a transparência escolhi a mesma técnica para representar a confusão da leitura, dessa vez usando o acrílico. Em cada página do livro, coloquei as palavras criadas por James Joyce, principalmente aquelas que não fizeram sentido algum para mim. Dessa forma, ao unir as páginas, as palavras uniram-se formando frase ainda mais confusas.

Elaborando o livro-arte "Fínigans Ueiqui" deparei-me novamente com a poesia concreta. James Joyce, utilizando a sonoridade e a criatividade, cria escritas poéticas, as quais fazem referência direta, por exemplo, quando você precisa ler a palavra criada por Joyce em voz alta para poder compreender seu significado, aos conceitos da poesia concreta, aprofundados anteriormente.

Além dessa relação com a poesia concreta, encontra-se novamente uma aproximação com a obra de Luise Weiss mediante características como a transparência, já citada, e a presença do "sonho" materializado em arte. O trecho a seguir refere-se a livros-arte de Weiss elaborados entre 1995 e 1997.

Certo dia, sonhei com um livro no qual eu pudesse capturar o tempo: devaneio, sonho, impossibilidade. Tratava-se de um livro que nunca se finalizava e que dizia do tempo. Quando acordei quis organizar este livro... em vão, imagens surgiam e novamente desapareciam e nenhuma se aproximava daquele sonho. Imaginei várias soluções gráficas, nenhuma me agradou. Aos poucos o projeto esvaeceu-se, para retornar novamente, em outro momento, o que aconteceu durante a pesquisa do doutorado, no qual o projeto voltou-se para os retratos e fotografias antigas (familiares inicialmente, e posteriormente de grupos anônimos) (WEISS, 2010, p. 1466).

No caso das obras de James Joyce, Luise Weiss e a minha própria, os sonhos fazem parte de nossa criação artística, assim como fizeram parte nas obras surrealistas e na de muitos outros artistas. O tempo apresenta-se nesta obra como ficção, como memória, como um aspecto da produção de artistas que utilizam formas encontradas em sonhos para a realização de sua arte. 


\section{"Outros"}

Um livro-arte “Outros” (2015), Figura 9, tem como questões norteadoras a autoria e a posse de uma obra de arte, porém a sua importância está na finalização de uma ideia, está na correlação entre os outros.

"Outros" é um livro-arte que foi criado de várias formas: primeiro, com a intenção de mostrar como organizo e assino meus próprios livros; em seguida, como discussão da autoria e da importância do leitor; e, por fim, para dar ao leitor/observador a oportunidade de realizar um livro-arte, utilizando um livro-arte pronto (produzido pelo "eu"), para criar um livro-interferido e se aproximar dos sentimentos que perpassam e perpassaram toda a dissertação por meio da criação de livros e das aproximações e diferenças entre artistas.

O objetivo principal era ter um livro-arte que discutisse a autoria da obra, ou melhor, que fosse simultaneamente meu e daqueles que com ele possam vir a interagir -

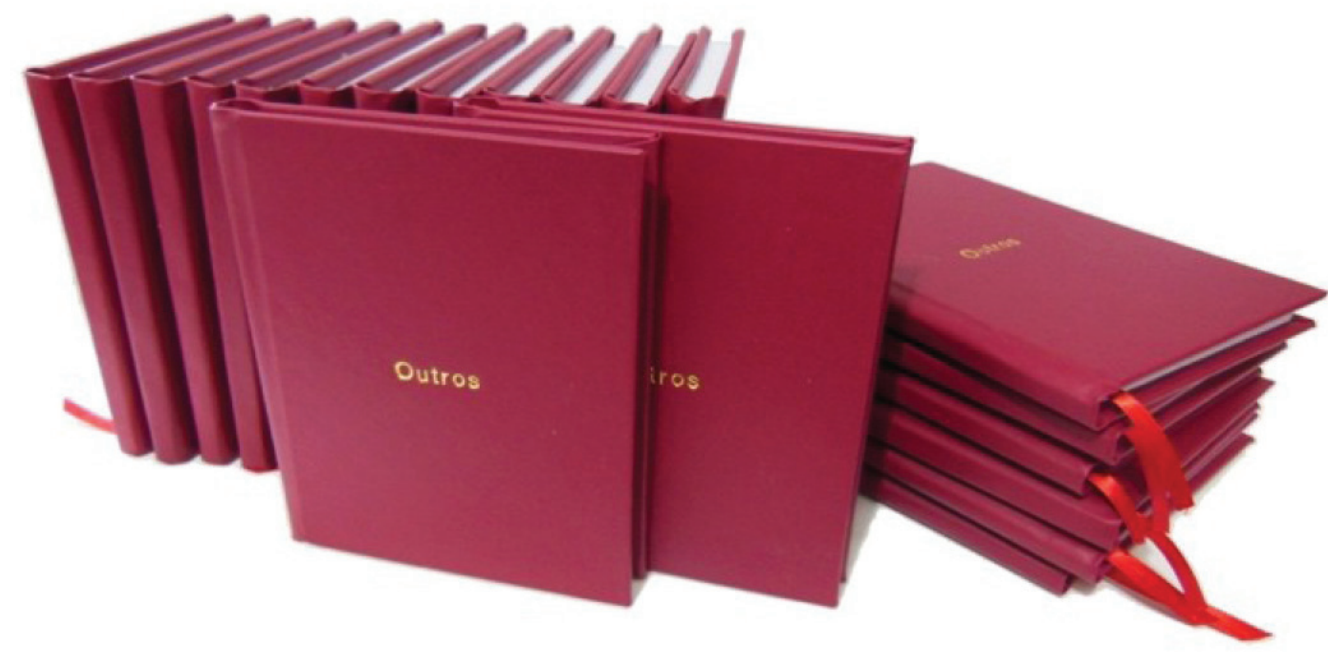

Fig. 9 - " Outros”, de Marina Attiná Jozala (2015).

Capa dura. $11,3 \times 15,5 \times 1,5 \mathrm{~cm}$.

Fotografia: Marina Attiná Jozala.

mas não era tão simples assim. Eu fiquei meses com a proposta fixa na cabeça de que deveria criar um livro primeiro, um livro comum: de poesias, de fotografias, de desenhos, um livro-arte simples usando desenho, gravura, alguma técnica que fizesse o livro surgir rapidamente. Por fim, isso levou vários meses, até que percebi que o que eu queria não tinha nada a ver com o conteúdo, mas com os conceitos envolvidos.

Criando um livro que incluísse apenas a folha de rosto, com o título, o nome do 
autor e o ano, e deixando o conteúdo em branco, eu pude deixar a cargo do leitor criar sua própria obra: ao realizar sua arte e/ou colocar sua assinatura, o leitor passa a também ser não somente dono do livro os "Outros", como também autor, já que o livro, antes, encontrava-se em branco.

Nessa obra convido outros a interferirem e/ou assinarem em livros realizados por mim, os quais passam a ser do "outro", sem deixarem de também serem meus.

Os "Outros", Figura 10, se apresenta como um dos exemplos que foi interferido, este foi entregue a uma amiga, Bruna Berger.

Quando recebi o livrinho "Outros", logo pensei em utilizá-lo para tratar também, de certa forma, sobre esse assunto. Isso porque me interessam dos outros as suas janelas, o que elas escondem ou permitem mostrar aos olhares alheios. Estamos cercados por janelas em cada parte e, a partir dessa pequena ou grande abertura, podemos ver e perceber um fragmento do mundo de cada outro sujeito. Assim, passei a desenhar janelas que vi por aí e o que me era permitido ver a partir delas, janelas de imagens encontradas na internet e outras imagens simplesmente inventadas a partir do meu imaginário (BRUNA BERGER, 2015).

O livro abordado a seguir, Figura 11, "Laranja do Brasil" (2011), de Luise Weiss, é um grande exemplo de obra que foi produzida a partir da colaboração de outros. Nele também estão presentes característica do tempo corporificado, representado por folhas naturais. Fazendo uma nova aproximação com a obra de Weiss, esse tempo corporificado também está presente no meu livro-arte "O Livro dos Livros", o tempo pessoal do artista, o tempo documentado, tempo esse que é vivenciado com memórias e objetos sig-
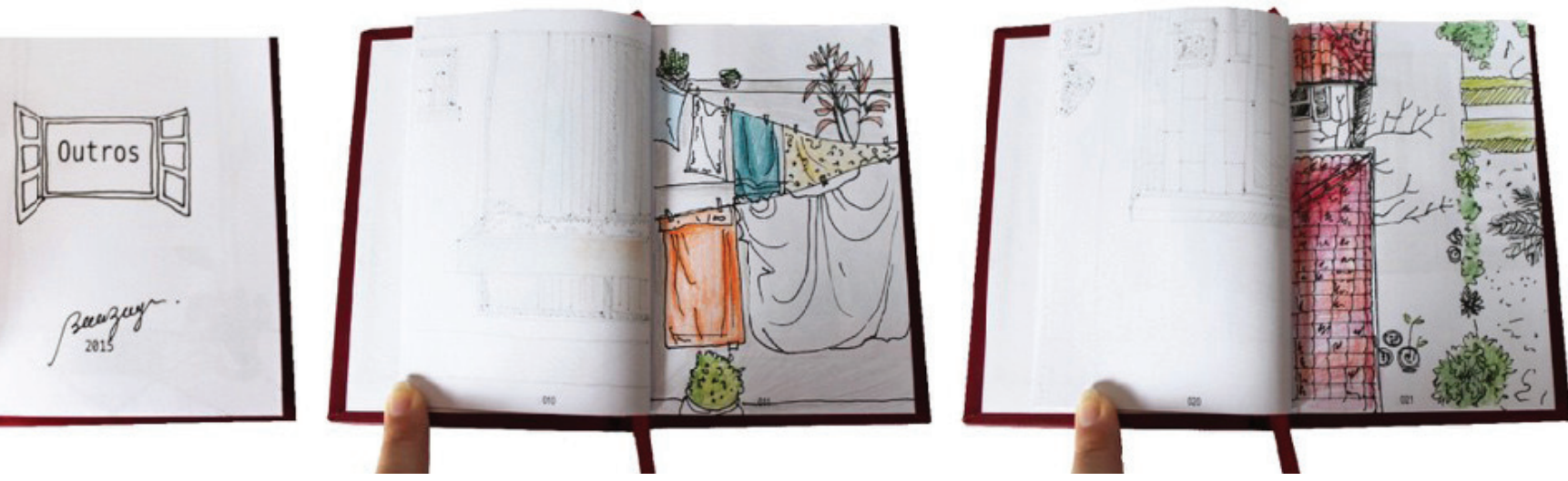

Fig. 10 - "Outros", de Bruna Berger e Marina Attiná Jozala (2015).

Capa dura. $11,3 \times 15,5 \times 1,5 \mathrm{~cm}$.

Fotografia: Marina Attiná Jozala. 
nificativos para o artista, tornando a obra de arte um diário, um objeto pessoal exposto para o outro. Esse livro-arte contém:

[...] pequenas relíquias familiares, cartões, anotações que ficavam dentro dos livros. Meu pai e avô eram médicos, tinha anúncios médicos e a "Laranja do Brasil" era alguma propaganda de material de exportação. Muitas vezes se enviava para algum parente que tinha ficado na Alemanha alguma encomenda do Brasil, principalmente após a II Guerra Mundial, quando as pessoas lá necessitavam. Na realidade, são pequenos "arquivos" familiares que constituem um acervo de cartas, cartões, fotografias, objetos que relatam uma época, a vida das pessoas. Seus destinos, nossos destinos (WEISS, 2015, entrevista).
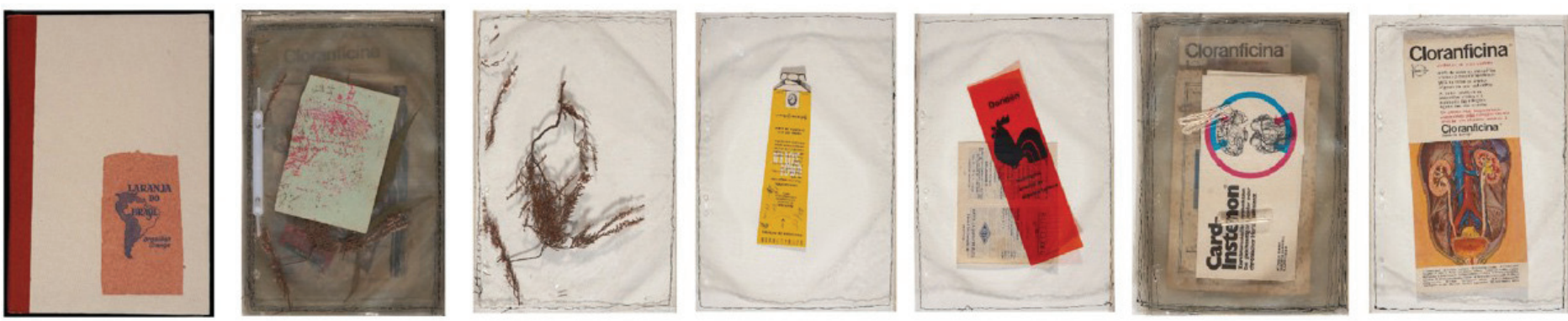

Fig. 11 - "Laranja do Brasil”, de Luise Weiss (2011). Diversos materiais. 32,5 x 22 × $5 \mathrm{~cm}$. Fonte: Acervo Luise Weiss.

Esse livro-arte, pessoalmente, mais do que qualquer outro livro de Luise Weiss que analisei para a pesquisa do mestrado, tocou-me, principalmente depois de receber as respostas da artista a uma entrevista que realizei por e-mail. Em sua fala, ela demonstra o quanto o "outro" é importante em seu trabalho, o quanto a influência de suas memórias está presente e também como isso atua em sua obra. Com esse livro-arte, ela realça as aproximações entre os meus trabalhos e os dela, retomando o foco desta pesquisa, através de suas vivências, interpretações, sensações e sentimentos. 


\section{Considerações Finais}

Percebi, no decorrer deste projeto, que, apesar de o livro-arte não ter um amplo reconhecimento no Brasil, nos últimos anos ele teve uma participação efetiva na arte nacional, figurando em livros, exposições e universidades.

Meu objetivo inicial era basicamente demonstrar que a linguagem do livro-arte está efetivamente presente no Brasil, apesar de não ter grande divulgação. Para tanto, escolhi apoiar-me na obra de Luise Weiss, uma vez que foi ela quem me apresentou esse universo dos livros-arte, além da identificação pessoal e artística que possuo com ela. A obra de Luise Weiss torna-se, ao longo da produção do trabalho, um forte apoio para a sua estrutura, contudo é a minha própria obra que passa a se destacar, conforme as diferenças transparecem e as aproximações tornam-se mais sutis.

Observando os livros-arte e os textos de Luise Weiss, percebi neles uma simplicidade que muito me sensibilizou. Não me refiro ao simplismo formal ou reflexivo de tais obras, mas sim à ausência de ostentação, o que torna seu discurso ainda mais amplo e potente. Não há como observar um livro-arte de Luise Weiss e não pensar em como foi produzido emotivamente. Percebi que, em meus livros-arte, busco imprimir essa simplicidade que tanto me fascina na obra de Luise Weiss e, através das aproximações, e também, diferenças encontradas nos trabalhos dela e nos meus, pude transpor esse aspecto de uma maneira mais clara em minha obra.

Ao longo da produção da dissertação, identifiquei, nas obras de Luise Weiss e nas minhas alguns pontos que julguei impossíveis de serem correlacionados. Dessa forma, o objetivo do trabalho de mestrado tornou-se apresentar a obra das artistas a partir do que subjaz a arte de cada uma e não apenas o que se aproxima, ou difere, em cada obra. Cada uma das artistas, Luise Weiss e Marina Attiná Jozala, possuem suas próprias características temáticas, conceituais e teóricas, assim como suas diferentes trajetórias e experiências. Em alguns momentos, tais características se encontram de maneira clara e, em outros, diferenciam-se quanto à técnica e o objetivo.

As aproximações que envolvem questões conceituais podem ser encontradas na relação do universo infantil presentes no meu livro "Curiosos Habitantes do Mar" (2014) e "Dentro do espelho" (2002) de Weiss; assim como em outros livros-arte que utilizam as formas de artes visuais da fotografia, da gravura; de temas familiares, da memória, entre outros: "No escuro" (2014) e "Outros" (2015). Os aspectos formais encontram-se na estrutura física: tipo de encadernação no caso de "Vitrais" (2014) e "Gira Gira" (2011); o uso da transparência, em meus livros-arte "Espelho d’Água" (2014), "Vitrais" (2014), e "Fínigans Ueiqui" (2015) e no livro de Luise Weiss, "Laranja do Brasil" (2011); além de outros aspectos discutidos no trabalho.

A partir das relações indicadas no trabalho, é possível perceber que as artistas têm em comum a utilização da linguagem visual do livro-arte como meio de liberação de sentimentos e pensamentos decorrentes de memórias e vivências. Além disso, ambas também evidenciam dar grande importância para a presença do "outro" em sua arte, 
como parte integrante ou personagem da obra, ou mesmo pela interação do "outro" com as obras finalizadas. Observa-se, ainda, a relevância da temporalidade, conceituada por Paulo Silveira, na linguagem visual do livro-arte como outro aspecto de aproximação entre a arte de Marina e Luise Weiss.

Por meio da pesquisa de mestrado pude me aproximar de uma artista por um viés diferente do que vinha fazendo até então. Com essa aproximação, encontrei diferenças e, dessa forma, defrontei-me comigo mesma, com características pessoais que podem ou não ser encontradas no "outro". Além da interação e do aprendizado adquirido pelo contato com a obra de Luise Weiss, pude deparar-me com artistas e autores antes pouco ou não conhecidos e, com isso, o meu interesse pela linguagem visual dos livros-arte cresceu ainda mais. As palavras de Paulo Silveira e de outros autores, demonstram aspectos da existência do livro e do livro-arte os quais eu desconhecia e que serviram como grande subsídio para a pesquisa.

Já ouvi dizer que a arte torna as pessoas mais humanas, e talvez seja isso que eu tenha encontrado no percurso do mestrado. Ao me deparar com a obra do outro, pude aprofundar-me em minhas próprias questões e me definir melhor como artista.

Descobri presentes em minha obra reflexões e características inexploradas anteriormente. Ao reunir nesse espaço os livros-arte que produzi para o mestrado, percebi qualidades que estavam presentes, mas não eram vistas por mim. Dessa forma, pude destrinchar minha produção e encontrar as verdadeiras aproximações entre as artistas selecionadas, unindo, assim, as características conceituais e formais dos livros-arte. Pude, então, valorizar a minha própria arte e fazer com que esta crescesse, evoluísse dentro da linguagem visual do livro-arte.

\section{Referências bibliográficas}

DERDYK, Edith (Org.). Entre ser um e ser mil: o objeto e suas poéticas. São Paulo: Editora Senac São Paulo, 2013.

FABRIS, Annateresa; COSTA, Cacilda Teixeira. Tendências do livro de artista no Brasil. São Paulo: Centro Cultural São Paulo, catálogo exposição [exhibition catalogue], 1985.

FRANCHETTI, Paulo. Alguns aspectos da teoria da poesia concreta. Campinas: Editora da Unicamp, 2012.

GALINDO, Caetano. Finnegans Wake / Finnícuus Revém. Revista Cult, ano 16, n. 176. Disponível em: <http://revistacult.uol.com.br/home/2013/09/finnegans-wake-finnicius-revem/> . Acesso em: 25 de agosto de 2015. Fevereiro de 2013.

NASCIMENTO, Ana Paula. Luise Weiss e Feres Khoury no Gabinete de Gravura 
Guita e José Mindlin da Pinacoteca do Estado de São Paulo. São Paulo: Pinacoteca do Estado de São Paulo, catálogo exposição, 2006-2007.

POESIA CONCRETA. Disponível em: <http://www.poesiaconcreta.com>. Acesso em: 22 de junho de 2015.

SILVEIRA, Paulo. A página violada: da ternura à injúria na construção do livro de artista. Porto Alegre: Editora da UFRGS, 2008.

SILVEIRA, Paulo. As existências da narrativa no livro de artista. 2008. $321 \mathrm{f}$. Tese (Doutorado em Artes) - Instituto de Artes, Universidade Federal do Rio Grande do Sul, Porto Alegre, 2008.

WEISS, Luise. Dentro do espelho. São Paulo: Cosac\&Naify, 2002.

WEISS, Luise. Luise Weiss. São Paulo: Editora da Universidade de São Paulo: Imprensa Oficial do Estado, 2004.

WEISS, Luise. No mar. São Paulo: IMESP, 2011.

WEISS, Luise. Retratos Familiares - In Memorian. 1998. Tese (Doutorado em Artes) - Escola de Comunicação e Artes, Universidade de São Paulo, São Paulo 1998.

WEISS, Luise. Caixa de Pepi: entre história, ficção e arte. $21^{\circ}$ Encontro da Associação Nacional de Pesquisadores em Arte Plásticas "Vida e Ficção / Arte e Fricção" - 24 a 29 de setembro de 2012. Rio de Janeiro.

WEISS, Luise. Livros-objetos e almanaques: marcas e deslocamentos. $1^{\circ}$ Encontro da Associação Nacional de Pesquisadores em Artes Plásticas "Entre Territórios" - 20 a 25 de setembro de 2010. Cachoeira, Bahia.

WEISS, Luise. Tão perto, tão longe: trajetórias. 20 Encontro da Associação Nacional de Pesquisadores em Artes Plásticas "Subjetividade, Utopias e Fabulações” - 26 de setembro a 01 de outubro de 2011. Rio de Janeiro.

WEISS, Luise. Livros de Artista, Livros-Objetos: Reflexões e Pesquisas. Casa Contemporânea, São Paulo. Disponível em: <http://casacontemporanea370.com/page/ livros-de-artista-livros-objetos/>. Acesso em: 9 de maio 2015.

WEISS, Luise. Passagens e Memórias. Museu de Arte de São Paulo, São Paulo, 2010. Disponívelem: $<$ http://masp.art.br/masp2010/exposicoes_integra.php?id=64\&periodo_ menu=cartaz $>$. Acesso em: 29 de julho 2015. 